\title{
Repertory Grid Technique in a participatory design of games for older people
}

\author{
Guilherme Fonseca (1) [ Pontifícia Universidade Católica de Minas Gerais | guilhermeitabaya- \\ na@gmail.com ] \\ Ezequiel M. Duque (1) [ Pontifícia Universidade Católica de Minas Gerais $\mid$ ezemendes@gmail.com ] \\ Rômulo B. Silva [D [ Instituto Federal do Norte de Minas Gerais |romulobatistasilva@gmail.com ] \\ Lucila Ishitani (1) [ Pontifícia Universidade Católica de Minas Gerais | lucila@pucminas.br ]
}

\begin{abstract}
With the aging society, there is an increasing need for services and software focused on older people. Digital games are one option of software to be provided as tools for entertainment, education, and well-being. However, to deliver these benefits, games must be developed according to the needs and preferences of older people. Seeking to improve the process of eliciting preferences from the target public, we applied Repertory Grid Technique (RGT) during the participatory design of a game. RGT is a cognitive interviewing technique based on Personal Construct Psychology, which has applications in different areas, including computer science. Although many articles discuss the application of RGT in the development of systems, we did not find, in the literature, any application of the technique with older people. We developed a game focusing on older people to understand better how such technique could contribute to game development, following action research methodology. We carried out three cycles of action research, all of which involved the use of RGT. The results indicate some benefits of using RGT instead of traditional semi-structured interviews. The main contribution of this work is to provide researchers with an initial understanding of the benefits of the application of the Repertory Grid Technique for the interviews with older people and how to use it during a participatory design.
\end{abstract}

Keywords: Repertory Grid Technique, Participatory design, Older people, Digital Games

\section{Introduction}

The world population is aging and undergoing a process of demographic change. According to the United Nations (2019), "there were 703 million persons aged 65 years or over in the world in 2019. The number of older persons is projected to double to 1.5 billion in 2050 ". This number will represent $16 \%$ or one-sixth of the world population.

The aging process causes several changes in the physical and mental aspects of a person. Older people generally suffer a reduced attention span when working on complex tasks and have cognitive losses that affect information processing. In addition, motor skills are also negatively affected by age (Gerling et al., 2010).

Digital games can help to diminish these effects. Ferreira and Ishitani (2015) conducted a study to identify the characteristics that digital games for smartphones should have so that older people feel the pleasure and the desire to use them. One of the identified results is about the expectation and interest of this target public in products and services that keep them updated, providing them with means of learning, having fun, interactivity, and communication with other people. However, few games are designed with a focus on the characteristics and needs of older people. For that, an application development process focusing on older people may apply Participatory Design (PD) (Kopéc et al., 2017; Bossen et al., 2013; Iacono and Marti, 2014; Santos et al., 2016).

PD involves the participation of the target audience during the development of an application to better adapt the final product to the user's needs. In addition, contexts like this, of developing an application for the older people, require the integration of PD with a social science approach such as Ac- tion Research (AR) (Ferrario et al., 2014). AR is a research methodology that seeks to involve society in developing practical solutions to their problems while generating scientific knowledge.

PD usually relies on workshop sessions, observation, and interviews to collect data from the participants (Kensing and Blomberg, 1998). Many interview techniques can be used. However, in the literature, we did not find any application of the Repertory Grid Technique (RGT) to survey requirements with older people during a participatory process. Thus, this study aimed to study and identify contributions from using RGT as an interview technique with older people during a PD. We developed a game for this public using Participatory Design integrated with Action Research to achieve this goal.

Repertory Grid Technique (Kelly, 1992) is a technique based on the theory of personal constructs. According to this theory, everyone has a set of personal constructs that serve as a basis for building mental models. These models determine how someone thinks and acts in their daily lives. RGT helps to understand how these models are built, helping to avoid misunderstandings between what one says and what one wants to say.

Throughout the development process, it was possible to perceive that the application of the RGT was important to arouse and deepen ideas and help the participants keep the focus on the problem.

This paper is organized as follows: Section 2 presents some important aspects of games for older people; Section 3 describes the main characteristics of the Repertory Grid Technique; Section 4 describes the methods adopted; Section 5 presents the action research cycles; Section 6 discusses the results; and finally Section 7 presents the conclusions, limi- 
tations of this work, and suggestions for future work.

\section{Digital Games for Older People}

The relationship between digital games and older people has been the subject of investigation for some time. In 1990, Whitcomb (1990) reviewed the literature carried out on this topic so far. According to Whitcomb, one of the first works was developed in 1976 and aimed to see how computers could help and enrich the lives of older people. An extension program was developed in which young people, who already had access to computers through schools, got involved with the older people in volunteer programs. Cooperative games were a component to assess the role of computers in society.

According to Whitcomb, the available research suggested several positive benefits for the older people who used wellselected games over a long period. Among them can be mentioned the improvement of motor skills such as dexterity, eye-hand coordination, and fine motor skills; the stimulation of social interaction; and the improvement in the speed of the tasks performed by the older people (Whitcomb, 1990). Nevertheless, the studies found that only a limited number of computer games were fun for older people. Many games were considered unsuitable for older people for several reasons, including the small size of objects on the screen, rapid movements or reactions, or inappropriate sounds.

Almost thirty years later, those problems were still unsolved. Salmon et al. (2017) stated that research teams worldwide have begun to recognize the potential of digital games and the challenge of designing games specifically for older people due to the typical changes in cognitive and sensorymotor functions with aging. Some recommendations collected from the literature are: reducing words per minute and background noise, improving the contrast of color and luminance on the screens, minimizing the number of steps needed to complete the tasks of the game, creating and emphasizing error messages and help materials, simplifying the rules and physical operations necessary for the game (such as button sequences) to reduce memory demands.

According to Salmon et al. (2017), differences in motivation to play due to age should also be considered. Whether or not older adults choose to engage with technology may depend on their assessment of relevance and advantages. Games may not be seen immediately as effective learning tools if older people do not realize their potential benefits.

Blocker et al. (2014) reported a preference for puzzles and educational games by older people. Concerning educational games, Silva et al. (2015) developed a game to teach older people how to use cell phone features, in addition to the primary phone functions: answering and making calls. The results indicate that the game helped the participants to learn to use several features, such as: taking and opening a photo, zooming in on a photo, using a contact list, searching the internet, and downloading an app. Despite focusing on older people, the game development process did not include representatives of the target audience. This situation raised one of the questions that motivated this work: would participatory design lead to different decisions than those made?

Reinforcing this line of thinking, more recently, Domin- gos et al. (2018) conducted a participatory design process to develop a game for cognitive training of older adults. In this work, the authors emphasize the importance of participatory design for better project development. However, they focused on the cognitive aspects of the game rather than the participatory process.

In turn, Lim et al. (2019) argue that with the improvements in technologies and the affordable price of mobile devices, researches in mobile games for older people are proliferating. They also state that studies have shown that games for mobile devices can increase the cognitive abilities of older people, provide a sense of pleasure and reduce the feeling of loneliness. In addition, the acceptance by the older people in smartphone games is growing, which differs from the previous findings of Salmon et al. (2017).

Concerning mobile educational games for older adults, Ferreira and Ishitani (2016) suggested that mini-games may help concentration, motivate the player to learn, and enable the best use of the mobile device used to play. Therefore, it may contribute to learning to include mini-games that arouse the players' attention and curiosity to discover what each mini-game has to offer and allow them to evaluate their performance in the game.

In their work, Lin et al. (2018) developed a serious game to stimulate older people's cognitive and physical functions. For the authors, the best way to mitigate the physical and cognitive health degenerations of older people is to stimulate related functions through an approach that uses games. Game-based training is proven to be more attractive than traditional approaches that do not involve them. In addition, digital games provide flexibility to meet the needs or deficits of each individual. For example, for older players to feel less anxious, a solution would be to adopt a slower scroll speed, confirming previous suggestions proposed by Salmon et al. (2017).

Concerning exergames, Fernandez-Cervantes et al. (2018) describe a physical exercise platform (adaptation of VirtualGym with motion capture by Kinect ${ }^{\mathrm{TM}}$ ) designed to support specialists in developing personalized exercise routines for older adults. As in this article, they discussed a participatory design study. They requested and analyzed feedback from ten older participants to evolve the VirtualGym user interface to meet the needs of the expected users.

Fernandez-Cervantes et al. (2018) also informed that the platform provides only positive feedback. This decision does not discourage users who have little experience with this technology, which this work similarly considers.

Fernandez-Cervantes et al. (2018) argued that the VirtualGym development process had not yet been finalized and believed that the participatory model adopted by the team would make VirtualGym's gaming experience serene for older adults. They validated the design decisions and guidelines that motivated them, like:

1. Simplicity is fundamental: elements that are only for entertainment purposes can distract the older audience. An example was the transformation of VirtualGym's background from a fantasy setting to a minimalist and spacious yoga studio.

2. All relevant information must be presented prominently 
and consistently because many older people have deteriorated peripheral vision. Thus, they may ignore information in many different places or near the edge of the screen.

3. Alternative information communication channels should be supported. Since older people may experience visual or auditory decline, instructions must be provided through texts and speeches.

4. Providing continuous feedback to older people about their performance can be ignored or cause frustration. Feedback must be timely and contextual.

5. Avatars must be anthropomorphic and with few details, but with elements that refer to an older appearance. The older people who participated in the study did not appreciate the fantasy/cartoon avatars in the original version of VirtualGym. They preferred the simply shaped humans developed by the team. This result contradicts what was identified by Duque et al. (2018), as older participants complained about avatars looking like older people.

As we can observe in the works presented, changes in cognitive and sensorimotor functions caused by aging affect the gaming experience. However, with the appropriate intervention of video games, the decline in the response speed of older people can be reversed though not entirely eradicated.

Design recommendations for games aimed at older adults, considering cognitive changes in learning, attention, perception, and performance of daily life activities related to age, should be weighed during game development. Therefore, simplifying the rules and physical operations necessary for the game (such as button sequences) are important actions. Otherwise, older people may believe they do not have enough skills to complete the game.

The development of activities focused on cognitive, perceptual-motor, and attention skills made possible by digital games promote therapeutic benefits in older adults' feelings of success and achievement.

Designing games specifically for older people is not a trivial task because they have their own needs, values, and culture. Thus, involving representatives of the target public in the development, as done by Fernandez-Cervantes et al. (2018), can bring several benefits that will improve this experience. Although important, we do not discuss cultural and value-oriented design in this work. This work evaluates possible approaches and benefits of applying RGT as an interview technique during a participatory design with older people.

\section{Repertory Grid Technique}

The Repertory Grid Technique (RGT) is a cognitive interviewing technique based on Personal Construct Psychology (Kelly, 1992). It has applications in various situations, such as education, market research (Niu and Easterbrook, 2007), and information systems, and information systems. However, its use in the last area is still limited (Curtis et al., 2008).

Repertory Grid Technique is a way of representing people's perception of a problem. In a repertory grid, the elements are the domain concepts (or other entities/objects) whose relations must be investigated (Lee et al., 2005). According to the theory, people create mental representations of events or objects using contrasting poles or constructs (Dey and Lee, 2017). For example, a person who needs to decide a place for dinner can think of multiple alternatives. Each of these alternatives is an element of the grid and is rated against contrasting poles like Near vs. Far, Dirty place vs. Clean place, possibly using a scale from ' 1 to 5 ' or ' 1 to 7 ' (Dey and Lee, 2017).

Table 1 is an example of a resulting grid of an interview conducted using RGT. In this example, the places in each column are restaurants evaluated. These places (Place 1, Place 2, Place 3 and Place 4) are the "elements". In the grid, each line represents a "constructor", which can be predefined or obtained from the participants. The interviewee also assigns values which, in this case, were previously agreed to be from 1 to 5 .

Table 1. RGT example

\begin{tabular}{|c|c|c|c|c|c|}
\hline & $\begin{array}{l}\bar{\Xi} \\
\frac{\tilde{E}}{2}\end{array}$ & $\begin{array}{l}\text { N } \\
\stackrel{\Xi}{\tilde{U}} \\
\frac{\pi}{\alpha}\end{array}$ & $\begin{array}{l}m \\
\stackrel{\Xi}{\tilde{E}} \\
\underline{\underline{E}}\end{array}$ & 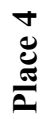 & \\
\hline Expensive & 2 & 2 & 3 & 5 & Cheap \\
\hline Far & 2 & 2 & 3 & 5 & Near \\
\hline Bad service & 1 & 3 & 4 & 5 & Good service \\
\hline Less food choice & 1 & 5 & 5 & 5 & More food choice \\
\hline Dirty place & 2 & 4 & 2 & 3 & Clean place \\
\hline
\end{tabular}

RGT can complement other tools and techniques used for requirements elicitation (Davis et al., 2006). Its usage can be extended in such a way that it can capture the stakeholders' intentions or expectations of the system-to-be in various contexts. This technique provides a good visualization of the mental representation of a subject (Dey and Lee, 2015). In summary, RGT can complement other tools and techniques used for requirements elicitation by (Davis et al., 2006):

- allowing analysts to elicit requirements that usually are not articulated by users;

- allowing analysts to elicit requirements in scenarios where they do not have "business knowledge";

- providing analysts and designers with a clearer picture of the context in which users perform tasks;

- providing a tool to understand the evolutionary nature of user needs.

Figure 1 shows the basic steps for applying RGT. To illustrate, imagine one study in which the goal (step one) is to develop a digital game for the older people population with their participation. The second step would be to choose older people who agree to participate in the development process. The interview includes steps $3,4,5$, and 6 . The third step is the definition of elements, which in this case could be digital games that the participants of the process would evaluate. These elements could be chosen by the researchers or by the participants. The fourth step would be the definition of the constructors, if not provided by the researchers. In step 5 , the participants fill the grid, which the participants validate in step 6. Finally, in step 7, the generated grids are analyzed. 
During the interview process, a researcher may use a laddering technique. It consists of a sequence of "how," "why," and "what" questions, to gain a broader understanding of elicited constructs. When applied, the laddering technique may help the researcher elicit the interviewees' values or preferences, impacting the development of a new product. More specifically, a sequence of "why" questions organize the constructs in hierarchical relationships, in which higherorder constructs "will be rated as having greater subjective importance to respondents than initial (subordinate) constructs in their ladders" (Neimeyer et al., 2001). In other words, beginning with concrete attributes, a ladder follows a line of reasoning to personal values. In this way, the technique may contribute to Value Sensitive Design (Friedman, 1996) or to Value-oriented and Culturally Informed Approach (VCIA) (Pereira and Baranauskas, 2015).

To better understand the relationship between RGT and requirements elicitation, we carried out a Systematic Literature Mapping. It began with the definition of a set of Research Questions. Based on the Research Questions, we defined a research protocol in which the search databases were selected and a sequence of filters was defined. Each filter was applied considering inclusion, exclusion, and quality criteria based on the Research Questions. We also defined a search string to be applied to the databases (Kitchenham, 2004).

The Research Questions defined for this work are:

- RQ 1. Why use RGT for requirements elicitation?

- RQ 2. How does RGT contribute to the requirements elicitation?

- RQ 3. What are the difficulties related to the use of RGT as a tool for requirements elicitation?

We searched the articles in January 2019. The IEEE Xplore and ACM Digital Library databases were selected as reference repositories of studies in sciences and engineering, mainly in the area of technology. In turn, we also selected ScienceDirect (SD) and Google Scholar (GS) because they present studies in multidisciplinary areas of interest for this work.

Initially, a search string was applied directly to the selected databases. The search string is a sequence of words derived from the Research Questions and connected through the logical operators AND and OR. We decided that the keywords would be repertory grid and requirements elicitation. After some tests in the selected databases using the keywords and their synonyms, we defined the following search string:

\section{("repertory grid" OR repgrid) AND ("requirements elicitation" $\boldsymbol{O R}$ "requirements engineering” $\boldsymbol{O R}$ \\ "requirement gathering”, OR "software requirements")}

It is important to note that we made some minor adaptations for each database according to its search engine rules.

The following inclusion criteria were used: i) article should be written in English or Portuguese; ii) article should be a full paper, with methods and results. Only one exclusion criterion was defined for this study: when there are two or more duplicate articles, consider only the most complete.

We used only one question as a quality criterion for this study: Does the paper answer at least two of the Research Questions?
The string search in the four search bases returned 661 articles. After applying inclusion and exclusion criteria, it was possible to identify 508 studies that could answer the research questions. From these, we selected 118 after reading the abstract, and 24 articles met the quality evaluation. Table 2 summarizes the results from each source and after the application of each criterion.

The following subsections present the answers to the research questions.

\subsection{Why use RGT for requirements elicita- tion?}

In nine articles, the authors stated they have chosen to use RGT because they consider it ideal when searching for tacit knowledge and structures of subjective thinking. RGT was also considered an easy-to-apply knowledge acquisition technique, able to provide a rich source of bias-free data, allowing data to be grouped or treated individually by different types of analysis that can be applied to the theory of personal constructs (Maiden and Rugg, 1996; Lee et al., 2005; Hudlicka, 1996; ur Rehman et al., 2013; Dey and Lee, 2017; Niu and Easterbrook, 2007; Niu and Easterbrook, 2007; Süner and Erbuğ, 2016; Curtis et al., 2008; Stary, 2007).

Besides that, some authors mention the ability of the technique to allow the interviewers to put themselves in the place of the participants, seeing the world through their eyes (de Boer and van Vliet, 2009; Dey and Lee, 2015; Lee et al., 2005; Niu and Easterbrook, 2007; Curtis et al., 2008; Pacheco et al., 2018). At the same time, it allows a reflection about the assumptions and different points of view found. In turn, Dey and Lee (2015) highlight that the technique helps identify the most relevant characteristics of a system. Moreover, Niu and Easterbrook (2007), Shaw and Gaines (1996), Niu et al. (2011), and Joseph (2017) say that the technique allows the detection of misunderstandings while helping to establish common points among stakeholders, avoiding common mistakes such as using different words to refer to the same idea and using the same word for different ideas. According to Davis et al. (2006), some stakeholders may have difficulty expressing and articulating ideas, a situation in which RGT can be of great help.

\subsection{How does RGT contribute to the require- ments elicitation?}

According to Stary (2007), "this technique provides a structured procedure for eliciting individual mental models with respect to a specific subject". Furthermore, access to such a map is of vital help in any research which involves people (Lee et al., 2005). Yousuf and Asger (2015) state that cognitive techniques as RGT allow analysis and collection of information up to the level of human thinking. Finally, Siau and Wang (2007) affirmed that RGT has the advantage of capturing user requirements and concerns about the complexity of a system.

RGT has a rich value in helping analysts express stakeholders' views of the problem world and the machine, explaining interrelationships among the entities in requirements models (Niu and Easterbrook, 2007). Besides, in RGT, knowledge 


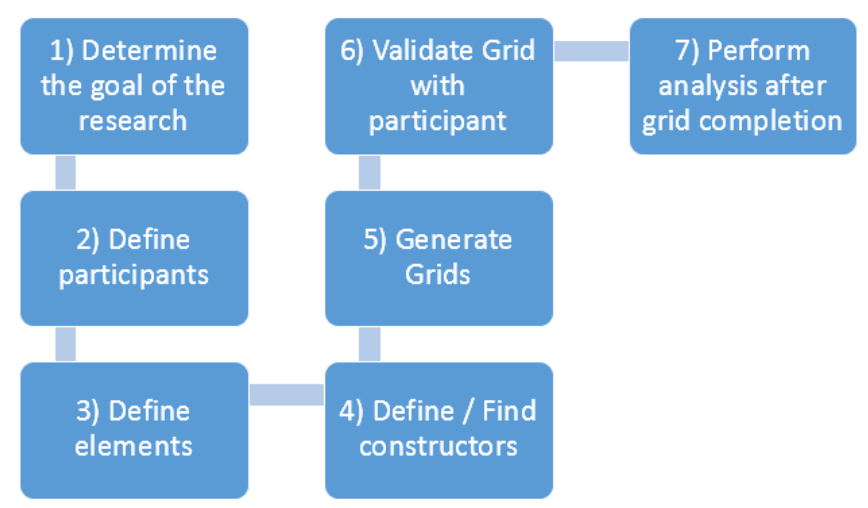

Figure 1. Basic steps for applying RGT

Table 2. Search results from each source

\begin{tabular}{l|cccc|r} 
Description & ACM & IEEE & SD & GS & Total \\
\hline Articles found in the base & 1 & 48 & 31 & 581 & 661 \\
Remaining after exclusion/inclusion criteria & 1 & 47 & 31 & 429 & 508 \\
Remaining after reading abstract & 1 & 16 & 5 & 96 & 118 \\
Remaining after quality evaluation & $\mathbf{0}$ & $\mathbf{6}$ & $\mathbf{2}$ & $\mathbf{1 6}$ & $\mathbf{2 4}$
\end{tabular}

is represented in a standardized format that supports statistical analysis (Maiden and Rugg, 1996). RGT is an option to filter design options based on user preferences in non-expert domains (Dey and Lee, 2015).

In the study of Davis et al. (2006), RGT contributed to identifying the users' needs in the context of their daily tasks. Based on their perceptions, the RGT prompted a discussion that revealed a "requirement" that was previously unknown. Still, according to the research, it is helpful to avoid an inappropriate allocation of needs. "This occurs when the perceptions of the developers about the desires of the users are used as surrogate specifications, although rational, that supplant the real needs of the users" (Davis et al., 2006). Finally, requirements learned from the application of the RGT helped guide the design (Davis et al., 2006).

Lastly, the discussions guided by the RGT help understand what the users want to do and why they want to do something. The experience with RepGrid enables to elicit requirements that have been missed or misunderstood because their definition was unclear (Davis et al., 2006).

\subsection{What are the difficulties related to the use of RGT as a tool for requirements elicita- tion?}

The studies found pointed some difficulties related to the applications of RGT. According to Hudlicka (1996), "while the initial phase of repertory grid analysis (the elicitation of entity differences and similarities) was very productive, the next phase proved to be difficult". Also, according to Hudlicka (1996), participants were discouraged from filling the grid due to its size. Hence, the research suggests that "the grids should be much smaller (less than 30 attributes) and the subjects should be encouraged in out shortly after the initial elicitation phase".

The participants of the study of Dey and Lee (2017) gave feedback stating that the repertory grid is not friendly
(Joseph, 2017). However, it was easier when they were allowed to use pen and paper to describe their requirements in a tabular format.

Süner and Erbuğ (2016) found difficulty in building constructors. Most of the construct poles were simply proposed by adding "not" in front of the original construct or describing the two poles as "easy to ... / difficult to ...". In addition, the research reports that the results can be harmed when the participants do not know the elements and that only presenting images is insufficient to obtain consistent results. "Lack of an equal amount of experience with each product resulted in limitations in participant comments as well as reflections on the imagined attributes of the product" (Süner and Erbuğ, 2016).

According to ur Rehman et al. (2013), "the efficacy of repertory grids is inadequate to delineate specific distinctiveness for the complex requirements". The application of RGT is time-consuming, and experts and analysts need to undertake lots of effort (Yousuf and Asger, 2015; Davis et al., 2006; Dehghani and Akhavan, 2017; Curtis et al., 2008). The technique may require two hours for each interview. However, the technique's richness to the communication between analysts and users offsets the efforts (Davis et al., 2006). Another factor that can make the technique time-consuming and tiring is when large elements sets are involved (Dehghani and Akhavan, 2017). In the end, "due to lack of understanding with the repertory grid, sometimes its steps were repeated which increased the length of the session" (Dehghani and Akhavan, 2017).

\section{Methods}

We applied Action Research (AR) methodology to evaluate the positive and negative aspects of the use of RGT with older people in Participatory Design (PD).

Action research is a collaborative research method in which researchers are directly involved with the community 


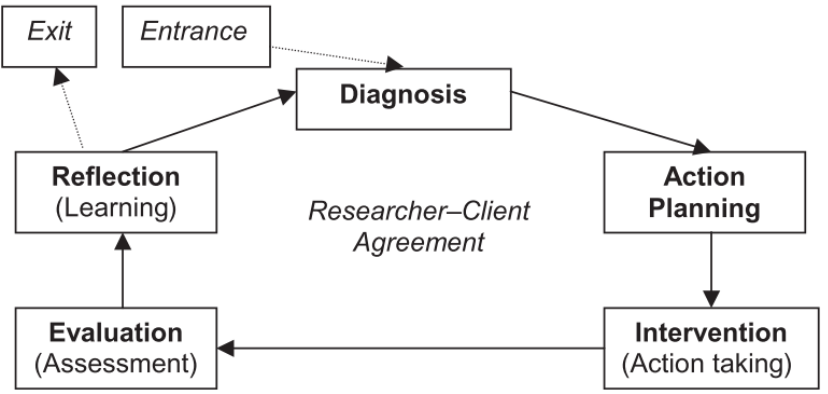

Figure 2. Typical Action Research Cycles from Davison et al. (2004).

to develop practical solutions and scientific knowledge. The focus of AR is more on the transferability of results than on their generalizability since solutions are often very contextualized and localized (Hayes, 2011). It is a cyclical method, in which each cycle usually has the stages of diagnosis, action planning, intervention, evaluation, and reflection (Davison et al., 2004), as shown in Figure 2.

The diagnosis stage corresponds to the identification of existing problems in the situation that requires improvement. Hypotheses are created about how to solve these problems.

The action planning stage includes the decision about what will be developed in the next execution cycle. The participation of the community is necessary for this stage. The stakeholders are informed about the hypothesis of the diagnosis stage. All the participants present their opinions about the direction of the project. After, the research team analyses what can be done considering all the suggestions.

The solutions planned in the action planning stage are executed in the intervention (action taking) stage, creating a new process or a prototype of a product.

In the evaluation stage, the product of the intervention stage is evaluated by the researchers and the community, discussing what went right or wrong and what still needs improvement.

In the reflection stage, the researchers and developers formalize what they learned to generate scientific knowledge and serve as a basis for improvements in the next cycle. This cycle is repeated until the team obtains a product that meets the target audience.

During all stages, the researchers, following AR principles, observe and record the situation, identifying positive and negative points in the relationships and communication processes between developers and volunteers and proposing improvements for the subsequent cycles. Thus, throughout the project, we seek to elicit the best practices to work with older people and develop a product that adequately meets the demands of users.

This study evaluates the execution of three cycles of an action research project to improve the development of a game for older people. In this project, the Repertory Grid Technique was used in the diagnosis phase of the three cycles to elicit requirements for the game's development.

\section{Case study}

To study the usefulness of RGT in the process of developing a serious game with a focus on older people, we designed a game to teach them how to use the most common features and applications on smartphones. We organized the game development process into incremental iterations so that, in each of them, the game under development included new elements. In total, three iterations, or cycles, were completed, and, for each one, we carried out the five stages of the AR.

In this section, we describe the participants of the process and the three cycles of Action Research. All of them included the use of RGT in the requirements elicitation process in each diagnosis stage.

\subsection{Participants}

We used the "snowball" strategy to invite participants for this study, starting from close contacts to the researchers involved in this project (Vinuto, 2014). When using RGT, "it is usual to interview a number of subjects, generally between 8 and 15" (Cunningham, 2010). However, we can find studies with less than five interviewees, such as the one conducted by Stary (2007).

Initially, ten volunteers aged between 60 and 76 years old participated in the process. Of them, only four participated in the entire process, which took approximately one year. They all signed an Informed Consent Form and voluntarily participated in the proposed activities without receiving any financial contribution. Because of that, the participants are also called volunteers in this article. The Ethical Committee approved this process (CAAE: 90795818.4.0000.5137).

Table 3 presents some characteristics of the participant. All of them use their cell phones daily.

Two male researchers from the Computer Science area conducted the participatory design sessions. Both of them were graduate students with professional experience in systems development. All collected data were discussed among the participants of a digital games research group. In addition to the two participants mentioned above, the research group was also composed of: a female professor of a graduate course, a male professor of a superior course in digital games, one female graduate student, and three students from a superior course in digital games (two male and one female), who contributed to the development of the prototype discussed in this work.

\subsection{First Cycle}

\subsubsection{Diagnosis}

In the first cycle, we planned to develop the game's basic structure and the first of its mini-games. In the diagnosis stage of this cycle, we sought to understand the problem defined as the project's starting point. We conducted the following activities:

\section{Literature review}

Initially, we carried out a literature review to get to know some current studies on games for older people. The main results are presented in Section 2.

2. Identification of desirable characteristics for educational games 
Table 3. Participants

\begin{tabular}{|c|c|c|l|c|l|}
\hline Participant & Gender & Age & Education level & Proficiency & Play games \\
\hline A & F & 65 & Graduate & None & Never \\
\hline B & F & 65 & High School & Much & Never \\
\hline C & M & 76 & Graduate & Little & Once a week \\
\hline D & M & 71 & High School & Little & Rarely \\
\hline E & F & 63 & Undergraduate & Little & Rarely \\
\hline F & F & 60 & Undergraduate & Little & Never \\
\hline G & M & 69 & Graduate & Little & Daily \\
\hline H & F & 74 & Undergraduate & None & Once a week \\
\hline I & F & 61 & High School & Little & Daily \\
\hline J & M & 61 & High School & Little & Never \\
\hline
\end{tabular}

RGT was used to identify characteristics of several game genres that were considered important by the participants. For this, six commercial games of different genres have been selected and made available for the volunteers to test them for a week. The games chosen were:

- Sonho de Jequi, an infinity runner with a social theme.

- Hit and Knockdown, a casual game of throwing balls in cans.

- Levar as Bolas para o Buraco, which means "Take the balls to the hole", a casual game that uses the smartphone gyroscope to control a ball.

- Candy Crush Saga, a popular puzzle game.

- Pife Online, a traditional card game.

- Magic Tiles, a musical game about playing the piano.

Ten volunteers participated in this stage. Their participation in the study consisted of playing the selected games for one week whenever they wanted to. After, they answered a questionnaire and participated in an interview using the Repertory Grid Technique.

The elements of each repertory grid were the games evaluated. The participants elicited the constructs during the interview. We requested the volunteers to compare three elements selected at random, asking them which two were more similar and what they differed from the third. In order to obtain more constructs, we applied the technique known as laddering to the answer to these first questions, asking why the constructs generated were important for the interviewee, thus seeking to obtain a new construct. After we elicited all constructs, the volunteers evaluated them for each element. The interviews were audio-recorded.

Each volunteer generated a grid. For example, Figure 3 shows the grid generated by volunteer $\mathrm{C}$ and Figure 4 shows the grid generated by volunteer $\mathrm{H}$. More detailed results were published in Mol et al. (2021).

As the constructs were generated during the interviews, each grid has a different set of constructs. The analysis of several grids with constructs generated by the interviewees is a technical challenge.

Identifying different user constructs with the same

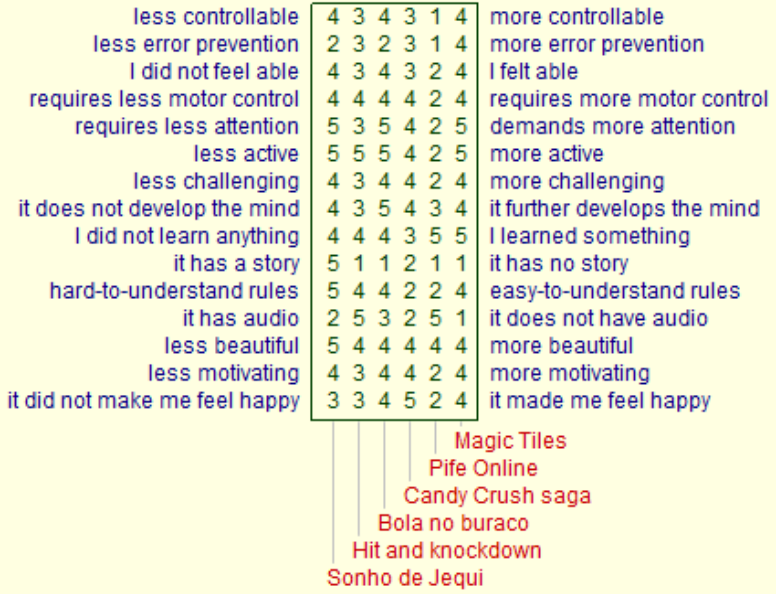

Figure 3. Repertory Grid generated for volunteer C

\begin{tabular}{|c|c|c|}
\hline less agility & \begin{tabular}{llllll|}
2 & 5 & 3 & 3 & 1 & 1
\end{tabular} & more agility \\
\hline requires less attention & 4154555 & demands more attention \\
\hline starts very fast & $\begin{array}{lllllll}3 & 3 & 3 & 3 & 4 & 1\end{array}$ & gives time to learn to play \\
\hline less immersive & $\begin{array}{llllll}3 & 1 & 3 & 4 & 5 & 3\end{array}$ & more immersive \\
\hline less motivating & $\begin{array}{llllll}4 & 1 & 5 & 4 & 5 & 3\end{array}$ & more motivating \\
\hline does not correspond to reality & $\begin{array}{llllll}4 & 1 & 4 & 4 & 5 & 5\end{array}$ & it corresponds to reality \\
\hline less controllable & $4 \begin{array}{llllll}4 & 4 & 3 & 5 & 5\end{array}$ & more controllable \\
\hline hard-to-understand rules & $\begin{array}{llllll}4 & 1 & 5 & 3 & 5 & 5\end{array}$ & easy-to-understand rules \\
\hline it has a story & 155355 & it has no story \\
\hline less beautiful & $\begin{array}{llllll}5 & 5 & 5 & 5 & 5 & 5\end{array}$ & more beautiful \\
\hline I did not learn anything & $\begin{array}{llllll}3 & 1 & 1 & 1 & 1 & 3\end{array}$ & I learned something \\
\hline I did not feel able & $\begin{array}{llllll}3 & 1 & 1 & 3 & 3 & 3\end{array}$ & I felt able \\
\hline \multirow{3}{*}{$\begin{array}{r}\text { it did not make me feel happy } \\
\text { it has audio }\end{array}$} & $\begin{array}{llllll}4 & 1 & 3 & 4 & 5 & 4\end{array}$ & it made me feel happy \\
\hline & $\begin{array}{llllll}3 & 5 & 2 & 3 & 5 & 1\end{array}$ & it does not have audio \\
\hline & \begin{tabular}{|}
$\left.\right|_{\text {Pife }}$ \\
Candy \\
Bola no bu \\
Hit and knoc \\
Sonho de Jequ
\end{tabular} & $\begin{array}{l}\text { agic Tiles } \\
\text { Online } \\
\text { Crush saga } \\
\text { uraco } \\
\text { kdown }\end{array}$ \\
\hline
\end{tabular}

Figure 4. Repertory Grid generated for volunteer $\mathrm{H}$

meaning and normalizing them with the same name requires careful analysis. Because of that, multiple coders chose one denomination for all constructs that had the same or similar meaning. All process was discussed and evaluated during meetings of the research group.

After filling in the Repgrid, we asked two additional questions for each volunteer: what did they like best and what did they like least in the games? Based on these responses and the evaluations of each game concerning the constructs, the following constructs stood out: more beautiful, demands more attention, made me feel happy, easy-to-understand rules, it further develops the mind, I 
felt able. These indicate that attention may be one of the challenging elements in the game and that a good appearance and developing the mind may be motivating elements to play a game. The clarity of the rules is an important thing to think about, especially when developing for older people. Some frequent terms in youth games may not be understood by older people so quickly. Due to age-related memory limitations (Ypsilanti et al., 2014), rules may need to be repeated more often during the game or to be easy to consult at any time.

Regarding aesthetics, visuals that attract the younger audience may be quite different from those that attract the older audience. With PD, it is possible to have a direct opinion on the visual characteristics of the game that most please the participants.

Each interview lasted about one hour.

3. Evaluation of educational games by the older people - A second stage of the diagnosis was to conduct a study with the participants to identify desirable and undesirable characteristics of a game for older people. For this, some free commercial games available in Google Play Store ${ }^{1}$ were selected for participants to play for two weeks.

To select the games, we considered a set of heuristics for usability evaluation of casual games for mobile devices aimed at older people (Santos et al., 2014) and a set of heuristics for gameplay evaluation aimed at older people (Machado and Ishitani, 2015). Six games were selected: Chili Crab, CodyCross, Duolingo, Librário, Sabores do Brasil and Defensores do corpo humano. Six participants agreed to collaborate: four women and two men. It was not necessary to have experience playing on a smartphone. All participants had a smartphone. However, it was not mandatory to have one, as the project team could lend the participant a cell phone during the participation period.

Four of these six volunteers continued to participate in the research stages and cycles following this diagnosis stage.

All games were presented to the participants, and we asked them to play the three they found most attractive. They were allowed to play for 15 days. We asked them to fill out a diary about their gaming sessions during this time. The diary was essential to record what they learned while playing and how they felt while playing. At the end of this period, we conducted semi-structured interviews.

From the diaries, it was possible to perceive pleasure in learning new things, demonstrated in phrases such as "Pleasure in learning a new vocabulary" and "Pleasure in getting it right for acquiring new knowledge". The participants also reported interest in the mental development that a game can provide, as in the sentence "In all the games I could observe the development of the right and left side of the brain, attention, dexterity, motor activity, memory, all important for the older people".

4. Validation of the diagnosis by the participants -

${ }^{1}$ play.google.com/store
Based on the participants' interest in learning, we proposed the development of an educational game. The objective of the game would be to teach how to use the smartphone better. In addition, we proposed minigames to teach specific content because minigames contribute to concentration and motivate learning (Ferreira and Ishitani, 2016). Everyone liked the idea proposed and suggested a cute and furry character for the game. After this validation, we considered the proposal to develop an educational game approved, and that the minigame format would be adopted, with the strategy of teaching different contents in each mini-game, for example, a mini-game to improve the precision and agility of touches.

\subsubsection{Action planning and intervention}

In these stages, we established a schedule for developing the game and interviews with the participants. Since we asked the volunteers to participate during the development process and due to the significant number of interviews during a long time, only four volunteers from previous experiments remained at this stage (volunteers $\mathrm{D}, \mathrm{E}, \mathrm{G}$, and $\mathrm{H}$ ). We defined that during the interviews, the participants would provide their opinions about several aspects of the game, such as the main character's characteristics, the scenario, and the interface elements. Based on the volunteers' choices, we made sketches of the game's visual style. Then visual elements were selected for presentation during interviews to choose more details and validate what we have created.

In addition, between one mini-game and another, the player would interact with a character who would give hints and help register the player's progress. To reach a wider audience, we planned for the mini-games to have different difficulty levels so that the game would be friendly to those who are not used to using a smartphone and offer a challenge to those more experienced. The mini-games should also have a progressive increase in difficulty to align with Mihaly's flow theory (Csikszentmihalyi, 2013).

We also defined that the navigation would be as simple as possible, without too many options on each screen to avoid confusing the user (Silva et al., 2014). Besides that, the buttons would be composed of icons and text to aid their understanding.

In this first cycle, we decided to develop a mini-game to hit the mole, to train the users in the precision of the touch gesture on mobile device screens. This mini-game consists of many holes displayed on the screen. Randomly, a mole appears in one of the holes and, after some time, enters back. The goal is to hit the mole with a touch while it is out of the hole. This mini-game requires quick and agile touches so that players have no time to press hard. It also requires touching multiple places on the screen, training accuracy.

We discussed possible elements that could affect the game's difficulty level, such as target size, the time between targets, target up time, target downtime, the possibility of fixing these times or including random factors, and simultaneous targets. For the prototype, we defined that there would be three types of moles with different colors. Each color would relate to a specific speed: green moles staying longer on the 


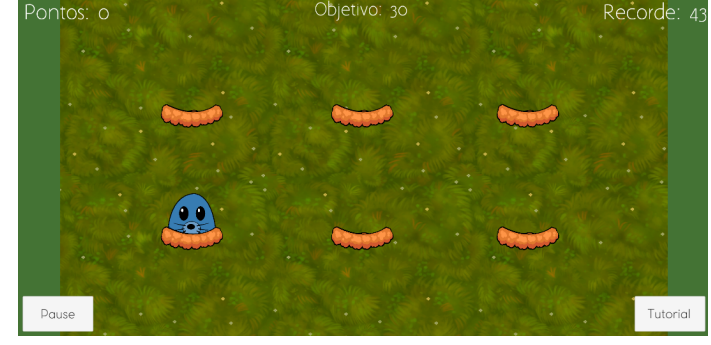

Figure 5. Mole Mini-Game

screen, yellow moles staying an intermediate time, and red moles staying a shorter time on the screen. The victory criterion would initially have a certain number of correct answers, and the defeat criterion would be a certain number of mistakes.

The prototype had three difficulty levels. The easy level had no red moles, the intermediate level had all moles, and the hard level had more holes than the previous level.

To avoid deviating from the proposal, we decided to present options for the participants to contribute to the game's construction at each step of the development. After we implemented their choice, we presented it for validation.

A record system enabled the participants to feel their progression and be encouraged to repeat and train the game to overcome their best scores. A tutorial was also developed, which appears only the first time the user enters the minigame but is available at any time. The tutorial is simple, easy to read, giving little information at a time so that the user can absorb it before moving on to the next instruction. A screenshot of the mini-game developed can be seen in Figure 5 .

\subsubsection{Evaluation and reflection}

The volunteers participated in the evaluation of the prototype created. For the prototype evaluation, we observed the volunteers while using the application. After, we conducted a semi-structured interview about the game.

The observation showed that the participants usually interacted with the device holding it with the non-dominant hand, using the dominant hand's index finger. All participants had this behavior, which previous studies already identified (Nicolau and Jorge, 2012). Younger users often play and type with more agility by holding the device with both hands and using their thumbs to type (Harman and Koohang, 2007). Training the use of the thumbs may bring more agility and reduce the effects of hand tremors.

We could also observe that although, in general, the older public needs simple games with well-explained rules, elementary games make them feel inferior or incapable (Carvalho and Ishitani, 2012).This situation may make the older people not interested in playing them. One of the volunteers' comments was, “...I'm finding it is very silly...". Simple games can be fun and educational without having childish characteristics. The participation of older people in the development process helps to balance being simple without being childish.

Another interesting observation was that most volunteers could not differentiate the tutorial from the game itself, trying to interact with the tutorial as if it were the game. From that, it seems interesting to develop more interactive tutori- als, making the difference between the tutorial and the real game clearer.

After observing the use of the prototype, we asked general questions, such as: "Do you have any suggestions for the improvement of this game?" or "Is there any subject you would like to learn through the game?". These questions did not generate contributions. One hypothesis is that the lack of suggestions is due to the participants' unfamiliarity with games and the mobile phones' features.

Next, more specific questions were asked, about elements of the interface, focusing on the clarity and legibility of its elements and the functioning of navigation in general.

In the answers about what they thought of the game, we could perceive an appreciation of the fact that the game exercises the mind and motor coordination, something that was highlighted as positive by the volunteers in statements such as:
"...it is good for that, it is agile, the older people have little agility...".
"I thought it was good too, but the player has to be very fast, right? But it's better to be fast because then we learn".
“...it will develop attention, agility and motor coor- dination... I think any game that will work on that is good".

\subsection{Second Cycle}

For the second iteration, we planned to develop a new minigame and improvements to the mole minigame from the first iteration results. From this cycle, all four volunteers were already in the habit of using mobile phones daily.

\subsubsection{Diagnosis}

In this diagnosis stage, we decided to identify which resources the volunteers were most interested in learning to determine the focus of the second mini-game. For this, we conducted an interview using the Repertory Grid Technique to compare smartphone elements concerning their usefulness, interest, and habits of use by older people. In this case, we presented a grid with the elements and constructs previously defined for the volunteers. Each of the volunteers should grade these elements. The Repertory Grid seemed to be an appropriate option for being a good tool for comparing and classifying elements, helping to direct the answers. Each interview lasted about 30 minutes.

We chose to present the grid with elements and constructs already defined to make the interview faster and less tiring. Besides that, perhaps, the participants were unaware that these elements existed due to their lack of smartphone usage. Constructs contributed to finding out whether volunteers knew how to use them, if they considered them useful and if they were interested in learning about each element. As elements, we presented some skills and resources referring to mobile phone use:

- Drag/Scroll: drag elements on the screen and navigate within applications using the scroll resource. 
- Zoom: use of the zoom resource in several applications.

- Photos: take, view, and forward photos.

- Messages: use of applications and resources to exchange messages.

- Map/GPS: use of GPS resources and map applications.

- Gyroscope: understand and use the gyroscope.

- Use of thumb: the ability to interact with the device using the thumb and not the index finger as observed in the previous cycle.

Before presenting the grid to the volunteers, we asked the question "Is there any smartphone feature you would like to learn or think it would be interesting for someone to learn it?" trying to obtain some of the volunteers' interests spontaneously, and we added them as elements in the grids. What appeared the most as an answer was the interest in learning how to use the device settings to activate and deactivate features, install applications and manage the memory. The interest in using social networks also appeared.

As the elements and constructs were predefined, it was possible to conduct quantitative data analysis. Figure 6 shows the grids with the predefined constructs. We took the average of the scores obtained by each of the predefined elements from the generated grids. What most influenced this score was the prior knowledge that the older people had about each element. The score was considered high for this analysis when the volunteer did not know how to use the resource, thus considering it a more interesting resource to be taught. Interest and importance had high scores for practically all the elements. The average scores can be seen in Table 4 .

Based on the results of the averages, the element with the highest score was using the thumb to interact with the phone, mainly because it is the element that the volunteers declared to have less knowledge and skill. This validated the perception that the use of thumbs to interact with the smartphone is an ability the older people have difficulty, but consider useful, thus having an interest in learning.

\subsubsection{Action planning and intervention}

Based on the diagnosis, we decided to improve the mole minigame, implementing two moles leaving a holes simultaneously, and the tutorial's inclusion of the suggestion of using the thumbs to play. Furthermore, we decided that the next mini-game would teach participants to "Drag" and to use the "Gyroscope". The gyroscope was the feature that obtained the second highest average, tied with the GPS. The drag feature did not have a very high average since the volunteers gave low scores to the pole "Already know/don't know" because they already knew it and how to use it. Nevertheless, the drag feature had the highest score for usefulness and one of the highest scores for interest, making it an interesting resource to offer to more novice users.

For this, we proposed a game in which the player must collect "bones" in the scenario, dragging them to a basket. In a possible simpler version, it would be enough to rotate the screen to see the scenery and drag the bones to a basket and then from that basket to another container. A more advanced version would follow a similar logic. However, the scenario would be larger than the screen, and the screen's orientation would determine in which direction one navigates the scenario. We decided to interview the participants using paper prototyping to validate the proposals and, from the validation, implement at least the simplest version of the game in this cycle.

During three weeks, we developed this new mini-game and improvements for the application in general, including the mole mini-game, based on the diagnosis and evaluation of the previous cycle.

\subsubsection{Evaluation and reflection}

In the second cycle, we presented a new digital prototype to the volunteers, and they made a new evaluation of the game. The volunteers demonstrated to feel effortless in playing the game and presented more suggestions, often suggesting more challenges. This situation suggests that as they gain familiarity with the project and the technology, the volunteers may have more confidence in giving opinions, which may become more relevant.

Thus, observing the volunteers interacting with the game is essential and helps understand and realize their needs. They often avoid making criticisms or get confused with some element and do not say anything. However, when watching them play, it is possible to notice these moments and even ask about them to identify possible improvements.

or the participants, the project was an opportunity to learn. It encouraged them to change their behavior concerning technology. For instance, one of the volunteers reported that he was training to type using his thumbs.

\subsection{Third Cycle}

For this cycle, we decided that the new mini-game would teach the use of some social networking functionality because the participants suggested it in the diagnosis stage of the second cycle. An interview was done in the diagnosis stage to define which feature to teach.

\subsubsection{Diagnosis}

To find out which social networking features would be most interesting to teach in the mini-game, we conducted an interview using Repertory Grid Technique. The elements were social networking features. We presented a grid to the volunteers with the following six elements previously defined:

- Like and share: features that allow users to show support or interest in something posted or share content with others.

- Follow and friendship request: features that allow a user to follow the activity of other people.

- Chat directly with friends: functionality to chat directly with others.

- Story: feature that summarizes and temporarily shares recent activity.

- Post: functionality to publish information and media files on the timeline so that others can see it.

- Group: feature that allows users to form groups of people with common interests to talk and share content on specific topics. 
Display Second Cycle Volunteer D

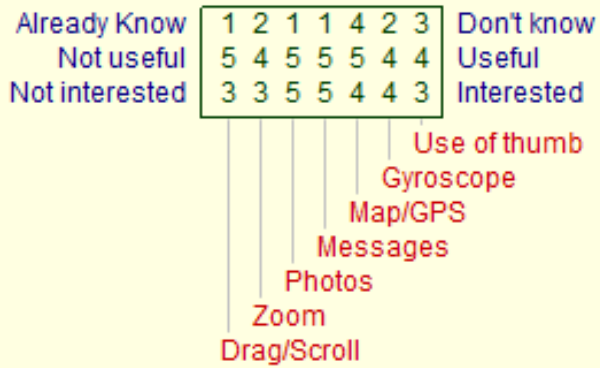

Display Second Cycle Volunteer E

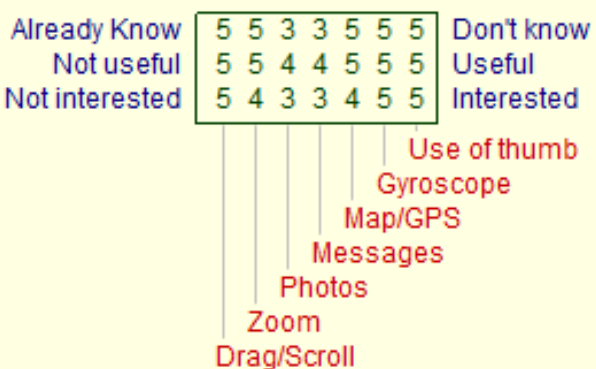

Figure 6. Two Repertory Grids generated for the second cycle

Table 4. Average scores for each element of the Repertory Grid

\begin{tabular}{r|l|l|l|l|l|l|l|l} 
& Drag/scroll & Zoom & $\begin{array}{l}\text { Photos (take } \\
\text { a photo, send, } \\
\text { download) }\end{array}$ & $\begin{array}{l}\text { Messages } \\
\text { (read, } \\
\text { write, } \\
\text { send) }\end{array}$ & GPS Map & Gyroscope & $\begin{array}{l}\text { Use } \\
\text { thumb }\end{array}$ & of \\
\hline Already know & 2 & 2.25 & 2.5 & 2.5 & 3.75 & 3.25 & 4.5 & Don't know \\
\hline Not useful & 5 & 4.75 & 4.75 & 4.75 & 5 & 4.75 & 4.75 & Useful \\
\hline Not interested & 4.5 & 4.25 & 4.5 & 4.5 & 4 & 4.75 & 4 & Interested \\
\hline Average & 3.83 & 3.75 & 3.92 & 3.92 & 4.25 & 4.25 & $\mathbf{4 . 4 2}$ &
\end{tabular}

To identify the elements that were considered most important to the volunteers, they were asked which elements they were most interested in learning and why. From these questions, we could extract the constructs of the repertory grid. Afterward, we asked the volunteers to evaluate each element with one to five for each construct. Each interview lasted about 20 minutes.

It was possible to notice that the participants tended to justify their choice almost always with the same reasons, and therefore only three to four constructs per volunteer were obtained. Figure 7 shows two grids, and Table 5 summarizes the score of each element.

Table 5. Average score of each element

\begin{tabular}{l|r}
\hline \hline Element & Score \\
\hline Like and share & 4.15 \\
Chat & 4.00 \\
Follow and friendship request & 3.43 \\
Group & 3.29 \\
Stories & 2.71 \\
Post & 2.57 \\
\hline \hline
\end{tabular}

The two elements with the highest average scores were Like and Share and Chat. Between the two, we decided to develop in this cycle a minigame focused on the second one. Both scored very close and analyzing the possibilities, a game simulating a messaging application seemed more interesting because it was the element that the volunteers declared to be the most difficult or complex.

\subsubsection{Action planning and intervention}

After the diagnosis stage, we decided to develop a mini-game that simulated an instant messaging chat system. The objective was to teach the use of this type of system and improve typing skills within social networks.
The game would simulate a conversation with other fictional characters, where the player would have to send messages with predefined texts. The player's progress would be measured by the time needed to type a message and the number of mistakes.

The possibility of including other elements such as emoticons, attachments, and contacts, was analyzed. However, we decided to begin with a prototype without these elements. This way, it would be possible to obtain the volunteers' contribution to developing a more complete and exciting game in the following cycles.

Figure 8 shows three screens of the developed mini-game. In the screenshot on the left, the dog says, "Type the following sentence: Glad you got a new cell phone. Now we can talk every day!" In the center screenshot, the dog says: "That's it! You got $98.8 \%$ of the letters right and finished in 3 seconds, totaling 1987 points. Now click Back (Voltar) and select a different friend!'. In the screenshot on the right, the dog says: "Congratulations! You win!" In this last screen, the user can also read the total number of points obtained, the percentage of correct answers, the total time spent in minutes and seconds, and a "Try Again" (Tentar de Novo) button.

\subsubsection{Evaluation and reflection}

We evaluated the prototype using a semi-structured interview with the four volunteers. At the beginning of the interview, we reminded the volunteers of the project's objectives before presenting the developed prototype. Then they were allowed to test the game for a few minutes.

After the tests, we asked the following questions:

- What is your opinion about the game?

- Do you think the game meets the objective of teaching how to use a chat?

- Do you have any suggestions to make it better meet this objective? 

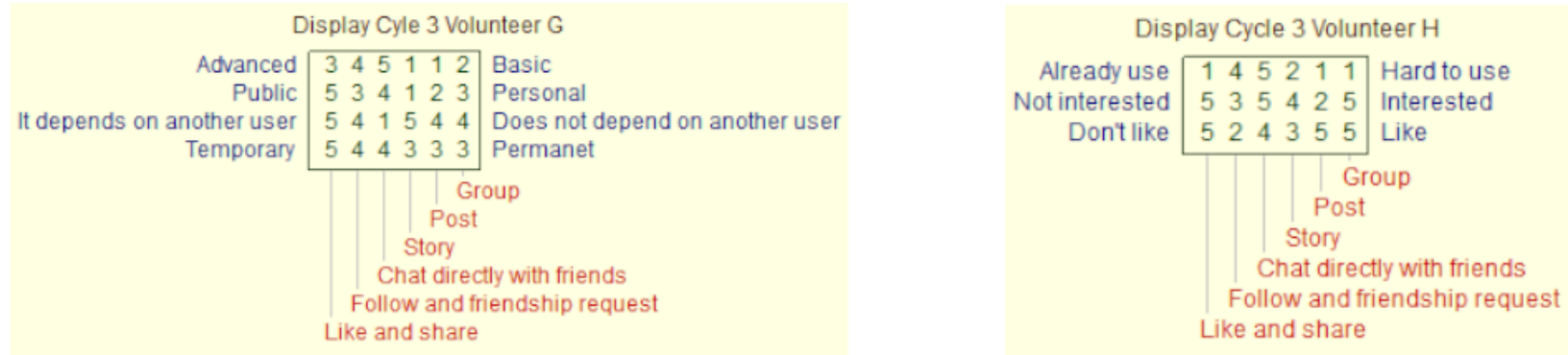

Figure 7. Two Repertory Grids generated for the third cycle

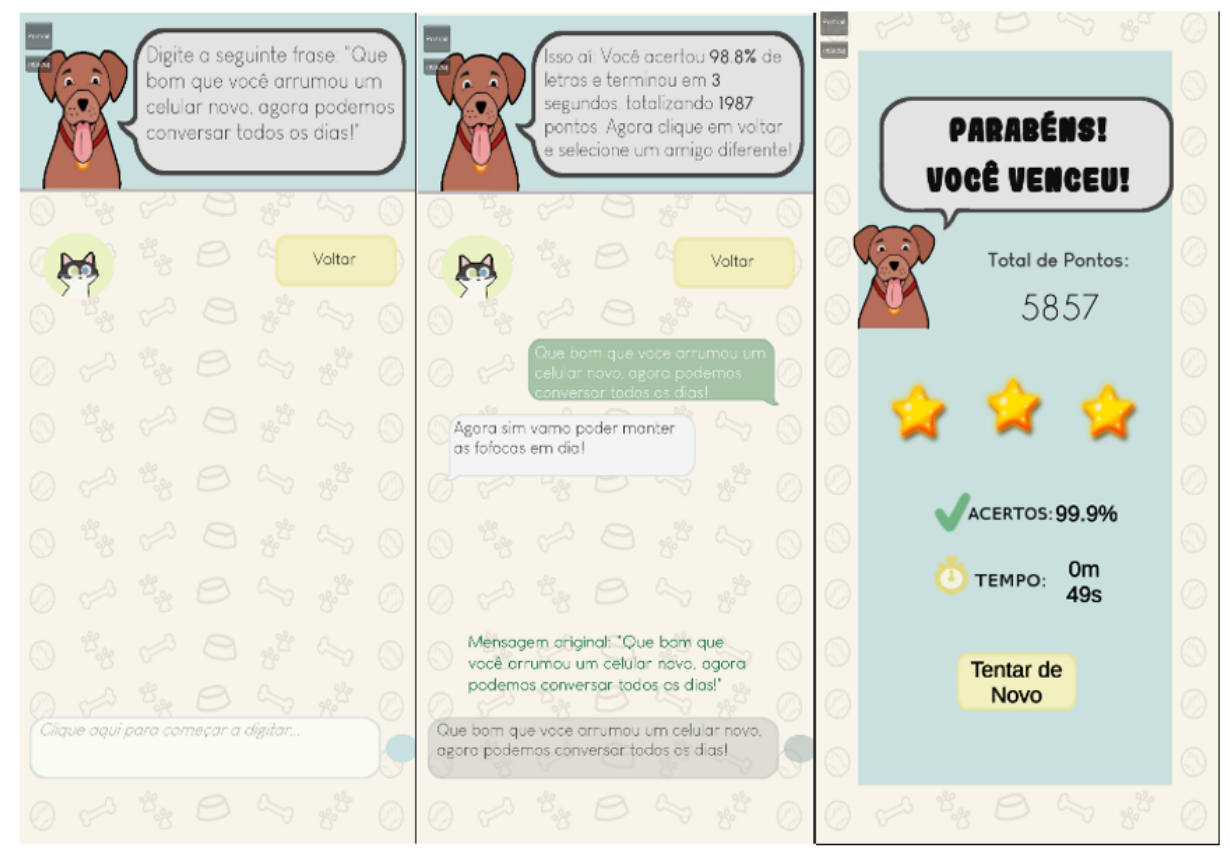

Figure 8. Screenshots of the mini-game that simulates an instant messaging application

- Do you have any suggestions to improve it and make it more fun?

As a result, we noticed that, in general, the participants liked the game and were motivated to improve their scores. It was possible to observe which mistakes the volunteers made and how they changed their behavior, trying to improve their typing ability. We also noticed that the volunteers started to worry about the correct spelling of the words and the punctuation of the sentences as they played, which can be seen in the answer below.

Interviewer: "Do you think the game meets the goal of teaching how to use chat?"

Volunteer: "For sure, because we don't pay attention, we type anyway, and we don't notice if we are making a mistake. Then the game gives us this opportunity, it shows us the percentage of mistakes, and we pay more attention. So it helps us a lot by making this correction, to write correctly and punctuate correctly...".

The participants presented the following suggestions for improving the game:
- Vary the difficulty level, starting with shorter sentences at the beginning and increasing the length of the sentences as the difficulty grows.

- Give continuity to the conversations and make the subject of one character have a relationship with the others, generating a story.

- Have more characters.

- Improve the readability of the text.

Besides, during the prototype evaluation, the volunteers were very enthusiastic about their scores and tried to improve them. This result shows that it might be interesting to include the display of all the scores obtained in the game.

Considering the information obtained during the evaluation, we could define several possible improvements to the game for future cycles. For example, the fact that the game displays a percentage of sentence errors was perceived as positive, motivating the volunteers to make fewer errors. However, there was no feedback on these errors. We considered the possibility of red coloring the wrong characters after sending the message to correct this aspect.

The suggestions provided by the volunteers should be implemented, especially the ideas of interaction between characters and story continuity. From this, it was discussed among the developers the possibility of creating some small 
quests, in which a character could ask to pass a message, forward a message, or share a contact.

\section{Discussion}

Pacheco et al. (2018) indicate that RGT is not widely used due to the emergence of recent techniques, "such as ontologies, collaborative techniques, and agile techniques that have been developed due to new communications channels or development methodologies". The fact that the technique is not widely used may make participants unfamiliar with the interview format (Dey and Lee, 2017). So when using the technique, it is essential to explain it and highlight the qualities of RGT.

In general, previous studies indicate RGT as a good technique for eliciting requirements (Niu and Easterbrook, 2007; Davis et al., 2006). RGT can have a considerable potential to uncover and exhibit interests in a particular context (Niu and Easterbrook, 2007; Curtis et al., 2008). We successfully applied the laddering technique with RGT in the diagnosis stage of the first cycle, which helped us identify constructs that were considered important for the participants and why.

In the initial part of the RGT application, it is essential to present the elements that will be part of the grid if the participants do not know them. As reported by Süner and Erbug (2016), the mere presentation of images may be insufficient for a good understanding of the participants. As a consequence, when the grid is filled, it may not have consistent information. In the first cycle of this study, we asked the participants to interact with the elements (games) for one week to avoid this problem. In the second and third cycles, we explained each element to the participants before the interview.

RGT's interviews may last for one to two hours. According to Dehghani and Akhavan (2017), the repetition of some steps in the Repertory Grid Technique makes it more tiring for the participants than other techniques. Combining RGT with other less time-consuming techniques can reduce overall time. Another way to reduce time is by providing the elements or constructs (Curtis et al., 2008), which we also have experienced in all the diagnosis stages. The decision to present the grid with only predefined elements and to survey the constructs during the interview allows us to obtain information about the motivation of the volunteers concerning the elements. However, this makes the interview longer. We highlight the second cycle when we provided elements and constructs, though care must be taken not to influence the participant, which may prevent meeting the appropriate requirements. To avoid this problem, before presenting the grid, we asked an open question so that the participants could spontaneously express their interests and preferences.

Siau and Wang (2007) stated that RGT has the advantage of capturing user requirements and concerns about the complexity of a system. In this work, during the execution of the AR stages, it was realized that conducting interviews using RGT presented itself as an appropriate strategy for cases in which the interviewee avoids talking about negative aspects, as they appear indirectly during the elaboration of the constructs. In addition, it enabled the generation of relevant con- structs to create a game aimed at the elderly audience.

Contrary to what was exposed by Niu and Easterbrook (2007), Shaw and Gaines (1996), Niu et al. (2011), and Joseph (2017), we may find situations where different words refer to the same idea or where the same words refer to different ideas. In order to avoid this type of problem, when the participant provides the elements and constructs, it is essential to register and clarify what each means.

One of the benefits of RGT is that it helps the participant keep the focus on the subject of the interview.

Finally, it seems that the advantages of RGT outweigh the disadvantages in many methodological contexts. The technique can be applied to many problems, especially if a researcher actively counteracts some of the disadvantages of the technique (Curtis et al., 2008).

Table 6 presents the summary of the contributions of the Repertory Grid Technique for requirements elicitation.

\section{Conclusions}

This study investigated the Repertory Grid Technique applied in a Participatory Design of a game for older users. RGT is not a new technique: it has existed since 1955 . We applied this technique in two different ways: with predefined elements and with predefined elements and constructs.

This study shows that the Repertory Grid Technique can be successfully used in the requirements elicitation stage with older people. Its application depends on good preparation by the interviewers since the technique is not frequently used compared to traditional interviews. .

RGT has the advantage of allowing qualitative and quantitative analyzes, and the possibility of generating cognitive maps is one of the most positive points. Other features are:

- RGT minimizes bias from the interviewer's side while developing an understanding of a domain from the user's perspective.

- RGT is a good way to collect requirements to be designed.

- RGT can help discover users' intentions and expectations regarding a particular system in different contexts, providing a good mental representation of a particular topic.

- With RGT, it is possible to determine what characteristics a system should have to adapt to a given context better.

One of the significant challenges of RGT concerns the aggregation of results. Although it is theoretically possible to aggregate the results, this operation faces several limitations. As each grid represents each person's interpretation, aggregating the results may mean simplifying each participant's mental model, contrary to the principle of personal construct theory. In addition, applying the technique can be time-consuming and requires dedication from experts and analysts to learn how to use the technique.

During the development process of the game, we could observe that the participants presented few suggestions. That could happen because many older people may not be profi- 
Table 6. Contributions of the Repertory Grid Technique

\begin{tabular}{|l|l|}
\hline Context & RGT Contribution \\
\hline $\begin{array}{l}\text { It can be difficult for older users, who are not always } \\
\text { technology savvy, to explicit what they want for an app. }\end{array}$ & $\begin{array}{l}\text { RGT enabled the generation of relevant constructs or im- } \\
\text { portant characteristics for them. When applied with the } \\
\text { laddering technique, it can help to elicit values, too. }\end{array}$ \\
\hline $\begin{array}{l}\text { It seems that older people do not feel comfortable to } \\
\text { present suggestions. }\end{array}$ & $\begin{array}{l}\text { We can identify users' preferences using RGT, a good } \\
\text { tool for comparing and classifying elements. }\end{array}$ \\
\hline $\begin{array}{l}\text { Older interviewees may like to tell personal stories and } \\
\text { may divert from the focus of an interview. }\end{array}$ & $\begin{array}{l}\text { RGT makes participants focus on the purpose of an in- } \\
\text { terview. }\end{array}$ \\
\hline $\begin{array}{l}\text { Older interviewees may avoid talking about negative as- } \\
\text { pects of an app. }\end{array}$ & $\begin{array}{l}\text { The negative aspects appear indirectly during the elabo- } \\
\text { ration or evaluation of the constructs. }\end{array}$ \\
\hline Long interviews may be tiring. & $\begin{array}{l}\text { It is possible to reduce the duration of an interview by } \\
\text { providing the elements or constructs of a grid. }\end{array}$ \\
\hline
\end{tabular}

cient in the use of technologies. So, it seems that some of the benefits of using RGT with them are:

- RGT is a good tool for comparing and classifying predefined elements;

- RGT allows participants to focus more on the objectives under discussion.

Although this study considered game development, the results can be applied to other kinds of software.

\subsection{Limitations and future work}

Concerning the participants, this work has two limitations. The first one is that the number of participants who followed the entire process was small, only four people. The second limitation is that all four participants were relatives of members of the work team. However, if the participation of the older people had been only to evaluate the prototypes developed, the fact that they were related would reduce the reliability of the results. Nevertheless, as the participation of the older people was to collect preferences and needs, the relationship with researchers does not affect the results. Despite that, considering a process that lasts for a year, even if researchers and participants did not know each other before the beginning of the project, friendship bonds are likely to occur. Then, even though all interactions were recorded and discussed among the teamwork, we suggest more studies with more participants.

In qualitative research, it is difficult to say which results can be replicated. The small number of participants makes it even more difficult to state that all results are generalizable. Thus, it is likely that some outcomes, such as a specific interest in learning a particular functionality, will be different with other groups of participants and at another time. However, we consider that, after the three cycles of RGT use, the main result of this study, which is the contribution of the RGT to the data collection process during the PD with the older people, can be applied in other contexts.

Considering the possibility of using RGT to understand essential values for the target public, we suggest more studies to validate and improve the comprehension of the use of RGT in the requirements elicitation process with older people.

\section{Acknowledgements}

This study was financed in part by the Coordenação de Aperfeiçoa- mento de Pessoal de Nível Superior - Brasil (CAPES) - Finance Code 001 .

\section{References}

Blocker, K. A., Wright, T. J., and Boot, W. R. (2014). Gaming preferences of aging generations. Gerontechnology : international journal on the fundamental aspects of technology to serve the ageing society, 12(3):174-184.

Bossen, C., Christensen, L. R., Grönvall, E., and Vestergaard, L. S. (2013). Carecoor: Augmenting the coordination of cooperative home care work. International Journal of Medical Informatics, 82(5):189-199.

Carvalho, R. N. S. and Ishitani, L. (2012). Motivational Factors for Mobile Serious Games for Elderly Users. In Proceedings of SBGames 2012, pages 19-28.

Csikszentmihalyi, M. (2013). Flow: The psychology of happiness. Random House.

Cunningham, S. (2010). Applying personal construct psychology in sound design using a repertory grid. In Proceedings of the 5th Audio Mostly Conference: A Conference on Interaction with Sound, AM '10, New York, NY, USA. Association for Computing Machinery.

Curtis, A. M., Wells, T. M., Lowry, P. B., and Higbee, T. (2008). An Overview and Tutorial of the Repertory Grid Technique in Information Systems Research. Communications of the Association for Information Systems, 23(3):3762.

Davis, C. J., Fuller, R. M., Tremblay, M. C., and Berndt, D. J. (2006). Communication challenges in requirements elicitation and the use of the repertory grid technique. Journal of Computer Information Systems, 46(5):78-86.

Davison, R., Martinsons, M. G., and Kock, N. (2004). Principles of canonical action research. Information systems journal, 14(1):65-86.

de Boer, R. C. and van Vliet, H. (2009). Writing and reading software documentation: How the development process may affect understanding. In 2009 ICSE Workshop on Cooperative and Human Aspects on Software Engineering, pages 40-47. IEEE.

Dehghani, M. and Akhavan, P. (2017). An experimental investigation of knowledge acquisition techniques. Journal of Management Development, 36(4):493-514.

Dey, S. and Lee, S. (2015). From requirements elicitation to 
variability analysis using repertory grid: A cognitive approach. In 2015 IEEE 23rd International Requirements Engineering Conference (RE), pages 46-55. IEEE.

Dey, S. and Lee, S.-W. (2017). Reassure: Requirements elicitation for adaptive socio-technical systems using repertory grid. Information and Software Technology, 87:160-179.

Domingos, G., Miura, B., Pas, A., Carthery-Goulart, M., and Brandao, A. (2018). Desenvolvimento de um protótipo de jogo com design participativo para treino cognitivo de pessoas idosas. In Proceedings of SBGames 2018, pages 97-106.

Duque, E., Nascimento, M. N., Fonseca, G., Soares, F., Pereira, H., and Ishitani, L. (2018). Uma análise sobre o desenvolvimento participativo de jogos educacionais voltados para a terceira idade. In Anais do XXIX Simpósio Brasileiro de Informática na Educação (SBIE 2018), volume 29, pages 555-564.

Fernandez-Cervantes, V., Neubauer, N., Hunter, B., Stroulia, E., and Liu, L. (2018). Virtualgym: A kinect-based system for seniors exercising at home. Entertainment Computing, 27:60-72.

Ferrario, M. A., Simm, W., Newman, P., Forshaw, S., and Whittle, J. (2014). Software engineering for 'social good': Integrating action research, participatory design, and agile development. In Companion Proceedings of the 36th International Conference on Software Engineering (ICSE Companion 2014), pages 520-523, New York, NY, USA. ACM.

Ferreira, R. and Ishitani, L. (2015). Jogos educacionais digitais para idosos: uma revisão sistemática de literatura. In Anais do XXVI Simpósio Brasileiro de Informática na Educação (SBIE 2015), volume 26, pages 404-413, Maceió, AL, BRA. SBC.

Ferreira, R. and Ishitani, L. (2016). Teoria fundamentada nos dados para o projeto da mecânica de jogo móvel educacional para adultos mais velhos. In Anais do XXVII Simpósio Brasileiro de Informática na Educação (SBIE 2016), volume 27, pages 360-369. SBC.

Friedman, B. (1996). Value-sensitive design. Interactions, 3(6): 16-23.

Gerling, K. M., Schild, J., and Masuch, M. (2010). Exergame design for elderly users: The case study of silverbalance. In Proceedings of the 7th International Conference on Advances in Computer Entertainment Technology, pages 6669, New York, NY, USA. ACM.

Harman, K. and Koohang, A. (2007). Learning objects : applications, implications, \& future directions. Informing Science Press.

Hayes, G. R. (2011). The relationship of action research to human-computer interaction. ACM Transactions on Computer-Human Interaction (TOCHI), 18(3):15.

Hudlicka, E. (1996). Requirements elicitation with indirect knowledge elicitation techniques: comparison of three methods. In Proceedings of the Second International Conference on Requirements Engineering, pages 4-11. IEEE. Iacono, I. and Marti, P. (2014). Engaging older people with participatory design. In Proceedings of the 8th Nordic Conference on Human-Computer Interaction: Fun, Fast, Foundational, pages 859-864, New York, NY, USA.
ACM.

Joseph, E. (2017). Survey on requirement elicitation techniques: It's effect on software engineering. International Journal of Innovative Research in Computer and Communication Engineering, 5:9201-9215.

Kelly, G. (1992). The Psychology of Personal Constructs, Vol. 1. Routledge.

Kensing, F. and Blomberg, J. (1998). Participatory design: Issues and concerns. Computer supported cooperative work (CSCW), 7(3):167-185.

Kitchenham, B. (2004). Procedures for performing systematic reviews. Keele, UK, Keele University, 33(2004):1-26.

Kopéc, W., Skorupska, K., Jaskulska, A., Abramczuk, K., Nielek, R., and Wierzbicki, A. (2017). Livinglab PJAIT: Towards better urban participation of seniors. In Proceedings of the International Conference on Web Intelligence, pages 1085-1092, New York, NY, USA. ACM.

Lee, C. C., Egbu, C., et al. (2005). The adoption of the repertory grid technique in capturing knowledge for refurbishment in the construction industry. In The Second Scottish Conference for Postgraduate Researchers of the Built and Natural Environment (PROBE), pages 317-328, Glasgow Caledonian University, Scotland, UK. Usir.

Lim, W. N., Lee, Y., and Anggoro, I. (2019). Augmented reality $3 \mathrm{~d}$ cubes puzzle bingo game for the elderly. In 2019 IEEE International Symposium on Haptic, Audio and Visual Environments and Games (HAVE), pages 1-6. IEEE.

Lin, Y.-H., Mao, H.-F., Tsai, Y.-C., and Chou, J.-J. (2018). Developing a serious game for the elderly to do physical and cognitive hybrid activities. In 2018 IEEE 6th International Conference on Serious Games and Applications for Health (SeGAH), pages 1-8. IEEE.

Machado, M. C. and Ishitani, L. (2015). Heurísticas para avaliação de gameplay direcionadas a idosos. In Proceedings of SBGames 2015, pages 333-342. SBC.

Maiden, N. and Rugg, G. (1996). Acre: selecting methods for requirements acquisition. Software Engineering Journal, 11:183-192.

Mol, A. M., Duque, E. M., da Fonseca, G. I. B., Machado, M. C., and Ishitani, L. (2021). Desirable characteristics of games for older adults. Entertainment Computing, 39:100440.

Neimeyer, R. A., Anderson, A., and Stockton, L. (2001). Snakes versus ladders: A validation of laddering technique as a measure of hierarchical structure. Journal of Constructivist Psychology, 14(2):85-105.

Nicolau, H. and Jorge, J. (2012). Elderly text-entry performance on touchscreens. In Proceedings of the 14th international ACM SIGACCESS conference on Computers and accessibility, pages 127-134. ACM.

Niu, N. and Easterbrook, S. (2007). Analysis of early aspects in requirements goal models: a concept-driven approach. In Transactions on aspect-oriented software development III, pages 40-72. Springer.

Niu, N. and Easterbrook, S. (2007). So, you think you know others' goals? a repertory grid study. IEEE Software, 24(2):53-61.

Niu, N., Lopez, A. Y., and Cheng, J.-R. (2011). Using soft systems methodology to improve requirements practices: 
an exploratory case study. IET software, 5(6):487-495.

Pacheco, C., García, I., and Reyes, M. (2018). Requirements elicitation techniques: a systematic literature review based on the maturity of the techniques. IET Software, 12(4):365-378.

Pereira, R. and Baranauskas, M. C. C. (2015). A valueoriented and culturally informed approach to the design of interactive systems. International Journal of HumanComputer Studies, 80:66-82.

Salmon, J. P., Dolan, S. M., Drake, R. S., Wilson, G. C., Klein, R. M., and Eskes, G. A. (2017). A survey of video game preferences in adults: Building better games for older adults. Entertainment Computing, 21:45-64.

Santos, L. G. N. O., Ishitani, L., and Nobre, C. N. (2014). Uso de jogos casuais em celulares por idosos: um estudo de usabilidade. In Proceedings of SBGames 2014. SBC.

Santos, M. M. T., Antonelli, H. L., Rodrigues, S. S., de O. Silva, C. L., Fortes, R. P. M., and Castro, P. C. (2016). Personalizing health-related ict interface and application: Older adults and elderly caregivers preferences. In Proceedings of the 7th International Conference on Software Development and Technologies for Enhancing Accessibility and Fighting Info-Exclusion, DSAI 2016, page 331-338, New York, NY, USA. Association for Computing Machinery.

Shaw, M. L. G. and Gaines, B. R. (1996). Requirements acquisition. Software Engineering Journal, 11(3):149-165.

Siau, K. and Wang, Y. (2007). Cognitive evaluation of information modeling methods. Information and Software Technology, 49(5):455-474.

Silva, R. B., Rocha, A. A., Nery, M. S., Mol, A. M., Ferreira, R., Silva, R. S., Yoshioka, S., and Ishitani, L. (2015). Labuta batuta: um jogo educacional móvel para adultos mais velhos. In Proceedings of SBGames 2015, pages 463-472.

Silva, R. S., Rocha, Á. A., Nery, M. S., Mol, A. M., and Ishitani, L. (2014). Viajando pelo mundo: um projeto de jogo para smartphone com foco em idosos. In Proceedings of SBGames 2014.

Stary, C. (2007). Intelligibility catchers for self-managed knowledge transfer. In Seventh IEEE International Conference on Advanced Learning Technologies (ICALT 2007), pages 517-521.

Süner, S. and Erbuğ, Ç. (2016). Evaluation of construct elicitation as a research method to obtain design-relevant data from children. METU Journal of the Faculty of Architecture, 33(2):19-43.

United Nations (2019). World population ageing 2019: Highlights (st/esa/ser.a/430). Available at: https://www.un.org/en/development/ desa/population/publications/pdf/ageing/ WorldPopulationAgeing2019-Highlights . pdf. Last access: 2021-04-01.

ur Rehman, T., Khan, M. N. A., and Riaz, N. (2013). Analysis of requirement engineering processes, tools/techniques and methodologies. International Journal of Information Technology and Computer Science (IJITCS), 5(3):40.

Vinuto, J. (2014). A amostragem em bola de neve na pesquisa qualitativa: um debate em aberto. Temáticas,
22(44):203-220.

Whitcomb, G. R. (1990). Computer games for the elderly. In Proceedings of the Conference on Computers and the Quality of Life, CQL '90, page 112-115, New York, NY, USA. Association for Computing Machinery.

Yousuf, M. and Asger, M. (2015). Comparison of various requirements elicitation techniques. International Journal of Computer Applications, 116(4):8-15.

Ypsilanti, A., Vivas, A. B., Räisänen, T., Viitala, M., Ijäs, T., and Ropes, D. (2014). Are Serious Video Games Something More Than a Game? A Review on the Effectiveness of Serious Games to Facilitate Intergenerational Learning. Education and Information Technologies, 19(3):515-529. 